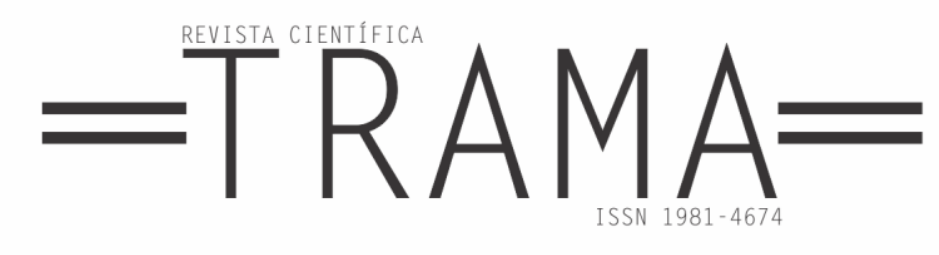

\title{
Oficialização da libras: Movimento surdo E POLÍTICA LINGUÍSTICA DE RESISTÊNCIA
}

\author{
Denielli KENDRICK ${ }^{1}$ \\ Gilmar de Carvalho CRUZ ${ }^{2}$
}

\begin{abstract}
Resumo: Objetiva-se com este estudo compreender o caminho percorrido pelas comunidades surdas brasileiras até a oficialização da Libras em 2002, pela Lei 10.436 e sua regulamentação pelo Decreto 5.626 de 2005. Utilizou-se de revisão de literatura como metodologia investigativa. $O$ referencial teórico baseia-se em conceitos bourdieusianos e nos Estudos Culturais. Verificou-se que, para a efetivação legal, o Movimento Surdo foi e é fundamental para as conquistas alcançadas. No entanto, a luta do Movimento continua para que políticas linguísticas sejam concretizadas a partir das leis.
\end{abstract}

Palavras-chave: Libras, Movimento Surdo, Luta.
Resumen: Se pretende con este estudio comprender el camino recorrido por las comunidades sordas brasileñas hasta la oficialización de la Libras en 2002, por la Ley 10.436 y su reglamentación por el Decreto 5.626 de 2005. Se utilizó de Revisión de Literatura como metodología investigativa. El referencial teórico se basa en conceptos burdisianos y en los Estudios Culturales. Se verificó que para la efectividad legal el Movimiento Sordo fue y es fundamental para las conquistas alcanzadas. Sin embargo, la lucha del Movimiento continúa para que las políticas lingüísticas se concreten a partir de las leyes.

Palabras clave: Libras, Movimiento Sordo, Lucha.

\footnotetext{
${ }^{1}$ Mestre em Educação pela Universidade Estadual de Ponta Grossa. Professora Tradutora Intérprete de Libras/Português na Secretaria de Educação do Paraná - SEED. deniellik@ yahoo.com.br

${ }^{2}$ Professor Doutor do Departamento de Educação Física da Universidade Estadual do Centro-Oeste UNICENTRO- Irati/ PR. gilmail@gmail.com
} 


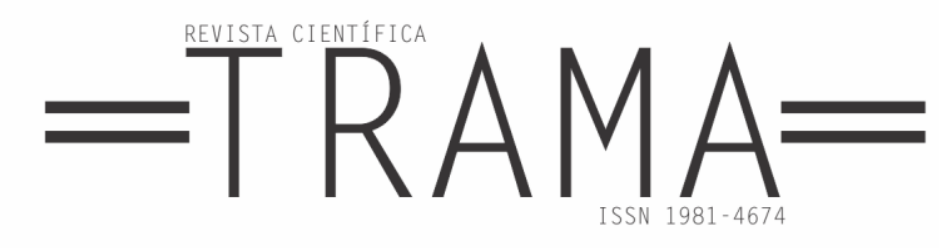

\section{$\mathbf{I}_{\text {NTRODUÇão }}$}

Comemoramos 15 anos da oficialização da Língua Brasileira de Sinais - Libras no Brasil. Sua trajetória e comprovação como língua pertencente a um grupo, uma minoria linguística, é resultado de forte envolvimento dos surdos dentro de movimentos sociais, que lutam por políticas de reconhecimento linguístico e contam com a participação de ouvintes que abraçam a causa e engrossam o grupo. Nesse contexto, o espaço acadêmico também teve e tem se mostrado imperativo para a qualificação e o prestígio necessários para afirmarmos, a partir de pesquisas científicas, que as línguas de sinais são línguas.

Nesse sentido, a constatação de Stokoe (1960), em seus estudos, sobre a Língua de Sinais Americana - ASL, apresentando-a como uma língua regida por regras gramaticais próprias, com campos de comunicação diferentes das línguas orais, não teve grande entusiasmo e receptividade por parte de seus colegas na academia, mas fomentou o início de pesquisas que aconteceriam em nível mundial sobre as diferentes línguas de sinais. No Brasil, as pesquisas nessa perspectiva iniciam-se a partir de 1980, sendo a década seguinte muito profícua em estudos acadêmicos (FERREIRA BRITO, 1984, 1990, 1995, 1998; KARNOPP 1994, 1999; QUADROS, 1997; FELIPE, 1998) que viriam a corroborar o que Stokoe (1960) tratou sobre a ASL, mas agora, sobre a nossa língua de sinais.

Cabe ressaltar a proibição do uso da língua de sinais como forma de comunicação e abordagem filosófica na educação do surdo, pós Congresso de Milão em 1880, mantendo-se por 100 anos, o que foi imensuravelmente prejudicial ao surdo, mas, ainda assim, não se eliminou a língua de sinais, ao contrário, ela foi mantida viva (SILVA, 2006).

A Comunicação Total - 1980 foi a brecha necessária para reintroduzir no campo educacional da surdez a língua de sinais - mesmo que naquele momento seu status não fosse de língua - mas que tomaria outras proporções nas décadas seguintes, enquanto reivindicação das comunidades surdas brasileiras pelo livre direito de comunicar-se e instruir-se na sua língua natural.

Nesse contexto, temos o Movimento Surdo como protagonista das lutas por políticas de valorização da surdez como diferença cultural e linguística. A seguir, nos deteremos a percorrer o caminho de luta empreendido pelo surdo para a conquista da oficialização da Libras no Brasil em 24 de abril de 2002, pela Lei ${ }^{\circ} 10.436$ (BRASIL, 2002), conhecida como Lei da Libras. Em seus cinco artigos, estabelece a Libras como língua oficial das comunidades surdas brasileiras.

\section{MOVIMENTO SURDO NO BRASIL}

O empenho do Movimento Social Surdo estimulou a organização de políticas públicas que buscam viabilizar ao surdo brasileiro a livre utilização da sua língua, inclusive como meio de instrução escolar. Nesse contexto, a ideia de formar comunidades surdas sempre foi bem-vinda e se constitui em ambientes de relações culturais e linguísticas profícuas ao surdo.

Mesmo com o longo período de proibição do uso da língua de sinais ao surdo, ela manteve-se em uso e em constante transformação, como acontece com todas as línguas vivas. A sua proibição não a extinguiu, por muito tempo o surdo teve que, clandestinamente, ensinar e aprender com seus pares linguísticos a língua de sinais (RAMOS, 2007; PEIXOTO, 2006).

Essa relação entre os pares e a organização em comunidades surdas proporcionou a articulação do surdo de modo mais político e aguerrido para a luta pela valorização da Libras como língua. Assim, nasce o Movimento Social Surdo no Brasil. Historicamente, teremos, a partir da década de 1980, a organização de diferentes movimentos sociais, período em que a ditadura militar como regime governamental acabava e o país vivia o êxtase da ideia de liberdade de expressão ofertado pela tão desejada democracia, constituída a partir desse momento. 


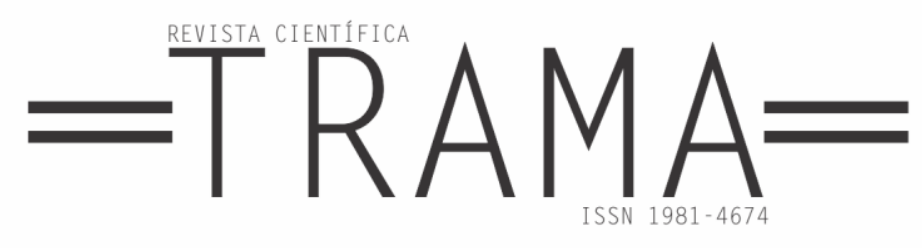

Brito (2013) afirma que as alterações observadas no governo do primeiro presidente civil, nos anos 1980, tiveram ações importantes, como a criação e reestruturação de órgãos públicos que eram responsáveis pelo preparo, implantação ou acompanhamento de políticas públicas para pessoas com deficiência e houve abertura para entidades representativas desse grupo.

Cabe fazermos uma referência aos estudos de Lane (1992), quando tratamos da surdez enquanto parte do grupo de pessoas com deficiência. A esse respeito, o autor destaca que, na década de 1960, nos Estados Unidos, foi difundido o termo deficiente auditivo, pelo que chamou de instituições audistas, que acreditavam que a criança surda seria melhor tratada se a terminologia deficiente fosse empregada; nessa perspectiva, o modelo clínico de tratamento de patologia é imperativo, mas para o autor, o termo não expressa a realidade do surdo. "Se os responsáveis pela criação do termo deficiente auditivo tivessem consultado a comunidade dos surdos, saberiam que 'surdo' não tem valor negativo, enquanto que 'deficiente auditivo' tem" (LANE, 1992, p. 90), o que implica numa forma de manutenção da dominação ouvintista sobre o surdo, que gera e é gerado pela violência simbólica ${ }^{3}$ (BOURDIEU, 2014).

Lane (1992) conclui que o termo surdo faz referência a uma cultura com linguagem visual-espacial e experiência partilhada em comunidade, ao contrário, o termo deficiente auditivo se limita a expressar uma condição física que coloca o surdo em posição subordinada aos ouvintes e descreditado pelos mesmos. Uma terminologia deve ser atribuída a um grupo cultural a partir dele mesmo, deixar que ele decida como deve ser designado, chamado e, assim, assumir posições dentro dos espaços sociais (LANE, 1992).

\footnotetext{
${ }^{3}$ A violência simbólica se caracteriza porque exerce uma força sobre os que a sofrem, e acontece na esfera das significações, do sentido que é dado pelos dominantes no mundo social. Ela tem como características ser oculta e arbitrária, "se institui por intermédio da adesão que o dominado não pode deixar de conceber ao dominante (e, portanto, à dominação) quando ele
}

Dito isso, não desconsideramos a importância que o movimento de luta das pessoas com deficiência teve e tem para o Movimento Surdo, enquanto espaço de organização e articulação das minorias. Mas existem ações para a desconstrução do conceito de deficiência como limitação e estigma, que são conceitos ainda não superados socialmente.

Podemos considerar alguns marcos importantes e pontuais do movimento das pessoas com deficiência: 1981, ano internacional das pessoas com deficiência, que ergue a bandeira da "Sociedade para Todos", luta pelo direito à plena participação na sociedade; em 1990, na Tailândia, acontece a Conferência Mundial sobre Educação para Todos; 1991, a ONU reafirma o conceito da "Sociedade para Todos", delimitando um decênio para que as mudanças fossem realizadas, se pontuava como maiores transformações a aceitação das diferenças individuais e o valor da diversidade humana; em 1992, foi proposto pelo Programa Mundial de Ações Relativas às Pessoas com Deficiência que a sociedade mudasse para que os direitos das pessoas com deficiência fossem respeitados; 1994, a UNESCO, com a Declaração de Salamanca (BRASIL, 1994), fomenta ainda mais as discussões sobre a necessidade da sociedade inclusiva para todos (BRITO, 2013).

Outras ações, nos anos seguintes, foram propostas pela ONU, no intuito de desenvolver ações políticas de valorização das pessoas com deficiência pelo mundo (KLEIN, 2006). O Brasil é signatário das ações supracitadas, o que permitiu que o movimento das pessoas com deficiência tivesse maior representatividade política e, ainda, acarretou conquistas de espaços antes nem debatidos, especialmente pela incorporação de boa parte das recomendações internacionais na legislação nacional.

não dispõe, para pensá-la e para se pensar, ou melhor, para pensar sua relação com ele, mais que de instrumentos de conhecimento que ambos têm em comum e que, não sendo mais que a forma incorporada da relação de dominação, fazem esta relação ser vista como natural" (BOURDIEU, 2014, p. 56). 


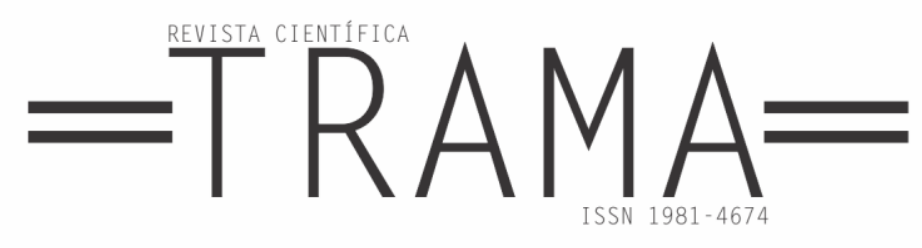

No entanto, sabemos que ainda estamos aquém do que preconiza a ideia de inclusão social das pessoas com deficiência (OMOTE, 2004; GLAT, 2006; GLAT et al., 2011; MAZZOTTA, 2011). Existe, inegavelmente, uma luta que se mostra desigual, os grupos de pessoas com deficiência formam uma minoria que precisa enfrentar um grupo dominante, maioria, que não tem interesse em alterar o status quo de legitimação e supremacia deles enquanto grupo detentor de poder. Entende-se os termos maioria e minoria no sentido bourdieusiano de relações de poder, que o autor denomina dominadores e dominados, que resulta na violência simbólica, velada nessa relação (BOURDIEU, 2014).

Portanto, as conquistas alcançadas pelas pessoas com deficiência demonstram um avanço considerável na tentativa de superar essas relações, no entanto, as demandas a serem ultrapassadas por esse grupo têm a incrível característica de se renovarem constantemente. É em meio a esse movimento de luta política de valorização das pessoas com deficiência que está incluído o Movimento Surdo, com suas demandas específicas e sua forma de reivindicar seus direitos.

O Movimento Surdo no Brasil foi também impulsionado pelo que acontecia em outros países, especialmente nos Estados Unidos, onde, desde a década de 1960, havia minorias que viviam a luta pelos direitos civis à liberdade. Nos Estados Unidos, houve a crescente participação de surdos em diferentes espaços - TV, cinema, teatro - e a busca pela superação da surdez enquanto patologia estava em uma constante crescente. Isso seguiu pelas décadas de 1970 e 1980, e "os anos 1970 presenciaram a ascensão não apenas do Orgulho Surdo, mas do Poder Surdo. Emergiram líderes entre os outrora passivos surdos" (SACKS, 1998, p. 76).

Já em 1988, um movimento impressionante mobilizou surdos do país todo, que lutavam para ter um reitor surdo dentro da Universidade Gallaudet, nos Estados Unidos, o que nunca havia ocorrido em 124 anos. A exigência da surdez para o cargo demonstrava não apenas uma condição, mas a necessidade de os surdos assumirem posições de destaque para tratarem de seus assuntos, com seus olhares e vivência surda. Houve passeata, barricada, ultimato aos ouvintes que dirigiam a instituição. Como resposta, foi-lhes afirmado que os surdos não estariam preparados para atuar no mundo dos ouvintes (SACKS, 1998).

Como reação à referida afirmação, os surdos estadunidenses intensificaram maciçamente os protestos. Após dias de movimentação e de fechamento da universidade pelos alunos, foi conquistado o primeiro reitor surdo. Isso significou muito para a comunidade surda local, mas despertou um empoderamento surdo que ultrapassou barreiras e motivou mundo afora outras comunidades surdas, inclusive a brasileira.

\section{A Feneis como espaço de luta}

O processo pelo qual a oficialização da Libras passou e como a organização dos surdos foi, nesse contexto, importante para a conquista é abordada ricamente em tese de Brito (2013). Há outros trabalhos que apresentam as questões do Movimento Surdo brasileiro no processo de legitimação da língua de sinais a partir de um determinado período histórico ou com uma abordagem que trata de modo mais geral o movimento (FERREIRA BRITO, 2003; MONTEIRO, 2006; THOMA; KLEIN, 2010; ASSIS SILVA, 2012). Sem dúvida, o trabalho de Brito (2013) mostra-se vasto em detalhes sobre o Movimento Surdo no Brasil, suas lutas e conquistas, especificamente, sobre a conquista da Lei da Libras (BRASIL, 2002).

$\mathrm{O}$ autor contribui ao apresentar a gênese do Movimento Surdo brasileiro e seus atores. Como supradito, o Movimento Surdo emerge da organização das pessoas com deficiência em entidades representativas de suas lutas e busca pela equidade social, "é assim que, nos primórdios dos anos 1980, a participação de pessoas surdas no então emergente movimento das pessoas com deficiência resumia-se a poucos ativistas vinculados a associações de surdos de alcance local" (BRITO, 2013, p. 87), e as 


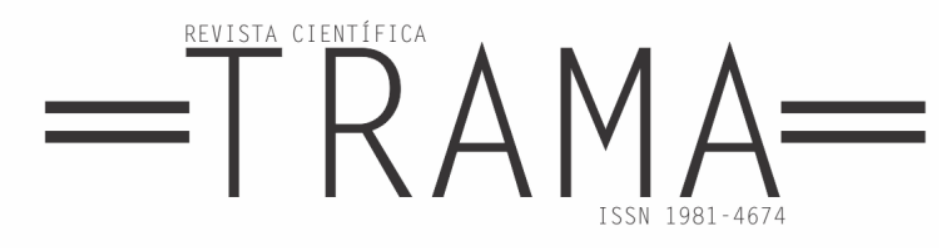

atividades realizadas dentro dessas associações eram de cunho esportivo, recreativo e de interação entre os pares. Houve uma guinada na década de 1990 dentro das associações, quando os surdos começaram a mobilizar-se em mais espaços na busca de conseguir mais recursos para suas lutas.

Não há nenhum exemplo que nos pareça mais significativo da dimensão e do alcance dessa evolução do que a trajetória da Feneis, a principal organização do movimento. Em 1987, quando ela foi criada pelos ativistas surdos, representava apenas 16 entidades de e para surdos de sete estados brasileiros e do Distrito Federal [...]. Dez anos depois, as instituições de e para surdos filiadas eram 88, situadas em 19 estados brasileiros e no distrito federal [...]. Além disso, membros surdos e ouvintes da sua diretoria ocupavam cadeiras permanentes nos colegiados de órgãos públicos federais, estaduais e municipais, assegurando a representação política do movimento nessas instâncias (BRITO, 2013, p. 87).

A Feneis - Federação Nacional de Educação e Integração do Surdo foi e é um espaço de organização dos surdos que possibilitou aos seus diretores, nas décadas de 1980 e 1990, expandirem o alcance sobre outros surdos para suas lutas e notícias em nível nacional. No Brasil, é, sem dúvida, o órgão de maior representatividade do Movimento Surdo, atuando com propostas para constituição de políticas públicas valorativas para os surdos e intérpretes de Libras (SOUZA, 1998).

A representatividade dos surdos crescia e cada vez mais agregavam-se militantes às causas surdas. Certamente, a maior delas era a legitimação e valorização da língua de sinais como meio de comunicação dos surdos, priorizando-a como meio de instrução dos surdos nos espaços escolares. Nesse momento ainda não tinha a configuração de educação bilíngue e nem a consciência do modelo socioantropológico, que hoje assumimos como bandeira de educação adequada ao surdo, e "ao que tudo indica, a defesa da língua de sinais pelo movimento social surdo, sobretudo pela sua principal organização [Feneis], desenvolveu-se nesse momento histórico ainda sob a configuração discursiva da comunicação total" (BRITO, 2013, p. 126).

Os ativistas surdos se empenharam na difusão da Libras através de cursos ofertados para ouvintes, e a Feneis se organizou para esse propósito, inclusive como modo de formar intérpretes de Libras. Fazia-se necessário que a língua não ficasse restrita, mas ganhasse maior visibilidade, o que ainda é um propósito da Feneis, que continua atuando na difusão da língua de sinais e na formação de instrutores surdos e intérpretes. Muitos intérpretes participaram ativamente da mobilização pela valorização e legitimação da Libras e não ficaram restritos ao trabalho de interpretação e tradução, mas empenharam-se na luta com os surdos.

\section{campo acadêmico como espaço de legitimação da língua}

Na década de 1990, assume-se, pela Feneis, a bandeira do bilinguismo como abordagem filosófica educacional mais apropriada aos surdos. Inicia-se uma frente de parceria da Feneis com as Universidades, uma forma de fortalecer a luta no campo acadêmico e dele para outros campos. Muitos envolvidos no Movimento Surdo estavam dentro das universidades, espaço de produção acadêmica. Destaca-se, nesse processo, as universidades federais do sul do Brasil. O V Congresso Latino-Americano de Educação Bilíngue para Surdos, 1999, organizado pelo Núcleo de Pesquisa em Políticas Educacionais para Surdos da Universidade Federal do Rio Grande do Sul - NUPPES/UFRGS, contou com pesquisadores, profissionais, familiares e líderes surdos de diferentes continentes e mostrou a força da mobilização política da comunidade surda (FERNANDES; MOREIRA, 2014). As autoras salientam que, anteriormente ao evento, houve um espaço auto-organizado de discussão sobre temáticas de interesse da comunidade surda, que resultou no documento "A Educação que nós surdos queremos", que futuramente pautaria o decreto federal que regulamentou a Lei da Libras em 2005. 


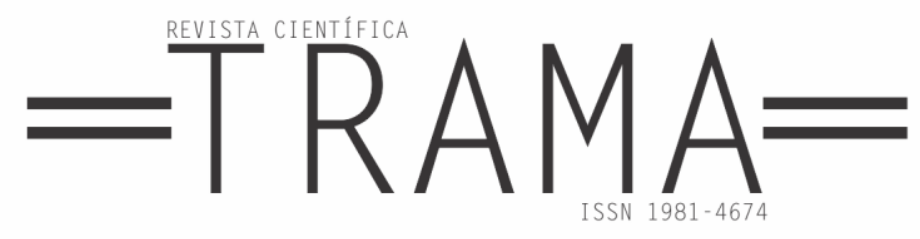

Essas reivindicações dão destaque à nova concepção de surdez, sujeito surdo e educação de surdos que se pretende afirmar, a partir do campo epistemológico dos Estudos Surdos com destaque ao papel central da língua, da cultura e da identidade surdas como campo discursivo de luta, como prática de significação, de produção de sentido sobre o mundo (FERNANDES; MOREIRA, 2014, p. 57).

Conforme o NUPPES foi ganhando força com suas pesquisas, novos espaços para a comunidade surda no campo acadêmico foram sendo conquistados, a mudança paradigmática após as pesquisas da área serem apresentadas, o discurso do surdo enquanto sujeito da educação especial é questionado, pois a perspectiva cultural e de identidade cultural passa a ser apresentada e o surdo é compreendido como sujeito de uma minoria linguística, na concepção de diferença cultural (HALL, 1996).

Moraes e Santos (2015) consideram que foi perceptível a urgência e a "consolidação da articulação do movimento social com os espaços de pesquisa em Educação. Essa articulação com a academia dá ao Movimento Surdo uma característica peculiar" (MORAES; SANTOS, 2015, p. 4), a inserção em um ambiente confere prestígio às pesquisas e a possibilidade de realizá-las nesse campo.

Nessa perspectiva, Barberena (2013) apresenta como a surdez foi tratada nas produções da ANPEd - Associação Nacional de Pós-Graduação e Pesquisa em Educação, de 1990 a 2010. A pesquisadora constatou que, na década de 1990, há duas perspectivas sobre língua de sinais. $\mathrm{Na}$ primeira, a língua enquanto sendo parte da perspectiva pedagógica da Comunicação Total, característica instrumental. A segunda, após 1996, com as lutas do Movimento Surdo, a perspectiva bilíngue é assumida nas produções. Na década de 2000, a autora assinala três questões que são recorrentes na ANPEd, no GT de Educação Especial e no GT Movimento Social, onde há pesquisas sobre a educação de surdos.

Primeiro, a língua de sinais como mediadora da aprendizagem do aluno surdo, como a ponte para o aproveitamento da língua portuguesa e suas estruturas gramaticais. Segundo, a língua de sinais como um elemento da cultura surda, todos a interagir e a participar para alcançar a condição desejada, na busca de formação de sujeitos autônomos e críticos. Terceiro, a língua de sinais como a regularidade que institui a comunidade surda e suas reivindicações políticas, culturais, sociais e educacionais, colocando outras discussões em pauta nessa esteira discursiva, como o intérprete e suas relações, além da escola e dos movimentos sociais (BARBERENA, 2013, p. 9).

A autora observa que as produções acadêmicas estavam intrinsecamente ligadas às demandas do Movimento Surdo, e viceversa, uma alimentando a outra. Essas produções e a representatividade que a ANPEd tem no meio acadêmico certamente geram um espaço de conquistas que foram se alastrando no campo acadêmico, em diversas Universidades do país.

Assim, a motivação para a conquista de educação bilíngue ao surdo, não como uma concepção pedagógica, mas como um modo mais assertivo de acesso de ensino (FERNANDES; RIOS, 1998), acendeu ainda mais a mobilização dos surdos no Brasil. Busca-se a garantia de utilizar livremente a língua de sinais como primeira língua - L1, pois identificam-se com a língua de sinais, utilizam-na diariamente como meio de comunicação e apontam que seu canal de interação - visual-espacial constitui uma forma específica de perceber o mundo e interagir com o mesmo.

A peculiaridade linguística dos surdos os assemelha a outros grupos étnicos que utilizam línguas minoritárias, como os indígenas. No entanto, o uso da língua majoritária - português - se impõe como possibilidade de interação em diferentes espaços formais, o que torna seu uso necessário na modalidade escrita, como segunda língua - L2 - para os surdos, apontando a característica bilíngue aos surdos (FERNANDES; MOREIRA, 2014).

Quadros e Campello (2010) afirmam que o reconhecimento da Libras em âmbito nacional, legal, possibilitou difundir a Libras 


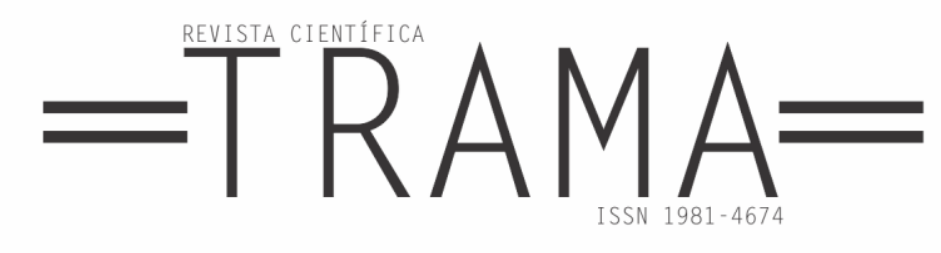

no país, e a educação ficou responsável por garantir a educação bilíngue para os surdos com o português como segunda língua. As autoras declaram que a língua de sinais é um elemento que constitui o ser surdo na relação com os demais e produz significados sobre si mesmos, demonstrando que as políticas linguísticas para as comunidades surdas formam um caminho sem volta.

O fato de contarmos com uma política linguística que reconhece a língua de sinais dos surdos brasileiros no contexto atual, em que o plurilinguismo está na pasta das organizações internacionais; o fato de contarmos com uma política nacional de educação que reconhece os surdos como bilíngues, garantindo-lhes o direito de acesso à educação bilíngue; e o fato de os surdos estarem presentes nas mesas em que são discutidas as formas que a educação passa a ter indicam que as negociações estão estabelecidas. Não há mais como negar esse caminho (QUADROS; CAMPELLO, 2010, p. 34).

De modo otimista, as autoras entendem que as políticas públicas, em especial as políticas linguísticas, demonstram um passo para construir a pluralidade linguística no país, com os surdos como protagonistas na elaboração das propostas políticas.

A partir desse contexto, observamos que o Movimento Surdo impôs um ritmo ao processo de oficialização da Libras em âmbito federal. As associações de surdos obtiveram muitas conquistas nos municípios. Antes de ser aprovada a Lei da Libras em 2002, já existia em diversas cidades o reconhecimento legal da língua de sinais como meio de comunicação dos surdos. Seguramente, essas conquistas locais refletiram na conquista em âmbito federal (THOMA; KLEIN, 2010).

\section{A oficialização da libras e SEUS DESDOBRAMENTOS NO ÂMBITO ESCOLAR}

$\mathrm{O}$ processo que deu origem à Lei da Libras (BRASIL, 2002) iniciou-se em 13 de junho de 1996. A senadora Benedita da Silva, do PT, apresentou o Projeto de Lei do
Senado $n^{\circ} 131 / 1996$. O Projeto tramitou nas duas casas legislativas por vários anos. $\mathrm{O}$ projeto original aponta que a principal reivindicação do Movimento Surdo era o reconhecimento da Libras como meio legal de comunicação e expressão e demais recursos de expressão a ela associados, apontando que se tratava de uma língua com gramática própria de natureza visualespacial.

Nos demais artigos propostos, sublinham-se ainda os seguintes pontos: (a) a obrigatoriedade do uso da Libras nas comunidades surdas do Brasil; (b) a obrigatoriedade das instituições educativas oferecerem essa língua como disciplina optativa nos currículos dos cursos de formação nas áreas de Educação Especial, Fonoaudiologia e Magistério; (c) a obrigatoriedade da administração pública, direta e indireta, assegurar aos surdos o atendimento nessa língua, por meio de profissionais intérpretes, nas repartições públicas federal, estadual e municipal, assim como nos estabelecimentos bancários, jurídicos e hospitalares; e (d) a obrigatoriedade do ensino dessa língua nos cursos para surdos (especiais ou integrados) desde a educação infantil ao ensino médio (BRITO, 2013, p. 2017).

Nos anos que se seguiram, a Feneis foi importante para impulsionar o Movimento Surdo às discussões que aconteciam no Senado e Câmara dos Deputados, sobre a Libras, para que não se perdesse o foco das reivindicações que se acreditava serem necessárias para os surdos. Foram promovidas diversas ações no sentido de pressionar o legislativo para a importância da Lei, e isso se deu por meio de abaixoassinados, manifestações no Congresso Nacional e por momentos de reivindicação corpo a corpo com os parlamentares (BRITO et al., 2013).

Após ser ratificada a aprovação do PLS $n^{\circ}$ 131/96 pelo Congresso Nacional, foi encaminhado pelo Senado à sanção presidencial. A Lei da Libras foi então sancionada em 24 de abril de 2002 pelo presidente Fernando Henrique Cardoso, na Lei $\mathrm{n}^{\circ} 10.436 / 2002$, como "meio legal de comunicação e expressão das comunidades 


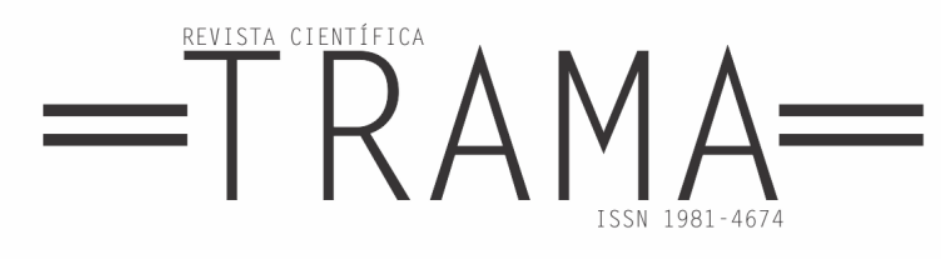

surdas no Brasil" (BRASIL, 2002). A aprovação e oficialização da Libras foi um processo rico de autoafirmação na constituição do Movimento Surdo. Representou uma vitória que desencadearia mais lutas pela efetivação da lei em diversos espaços.

Três anos depois, a Lei da Libras foi regulamentada pelo Decreto Federal $n^{\circ}$ 5.626 (BRASIL, 2005). Este decreto institui várias ações para a inclusão dos surdos em diferentes espaços sociais, tendo como ponto de partida o reconhecimento da Libras como língua das comunidades surdas brasileiras e a educação bilíngue um direito genuíno no processo de escolarização. Foi estipulado prazo de uma década para se implementarem as ações propostas. Passado esse decênio, certamente devemos investigar cientificamente o quanto as ações contidas no Decreto foram levadas a cabo e como reverberam, especialmente no contexto educacional nacional.

Cabe salientar que as reivindicações do Movimento Surdo apontam a educação bilíngue como necessária, mas a fragilidade como a inclusão escolar do surdo tem acontecido no Brasil compromete o sucesso da proposta, nesse espaço. Desse modo, é importante compreender que ainda há controvérsias entre o prescrito e o realizado na educação de surdos.

Nascimento (2017) auxilia no entendimento de que há diferenças na construção dos documentos legais existentes, ao tratarem da educação dos surdos:

A Política de Educação Especial na perspectiva da Educação Inclusiva é fruto da afirmação de princípios anunciados em diversos documentos internacionais e nacionais (BRASIL, 1990, 1994; 2001) que trazem como pano de fundo a democratização da educação. Já o Decreto n ${ }^{\circ}$ 5.626/2005 materializa os anseios do Movimento Surdo e dos pesquisadores do campo dos Estudos Surdos. A perspectiva destes dois documentos vai denotar a antiga tensão no debate sobre o lugar da educação bilíngue de surdos: o domínio da educação especial ou um campo específico de conhecimento, muito mais relacionado com as questões que envolvem a discussão sobre a diversidade cultural e linguística de grupos minoritários (NASCIMENTO, 2017, p. 48).

A autora nos apresenta a realidade das políticas públicas destinadas à educação especial e inclusiva, que nem sempre contemplam a necessidade dos surdos e suas exigências. Outro exemplo a se considerar aconteceu a partir de 2010 e culminou com a vitória do Movimento Surdo e suas reivindicações contempladas no do PNE 2014-2024 - Plano Nacional de Educação (BRASIL, 2014). Quando à época da participação dos surdos como delegados no CONAE - 2010, suas propostas de educação não foram contempladas e iniciou-se um embate histórico, com inúmeras manifestações e passeatas dos surdos em diversas cidades e, em especial, em Brasília.

Esperava-se que o documento final da Conferência contemplasse a demanda colocada pelos delegados surdos sobre a efetivação das escolas bilíngues. O que se viu foi a correlação de forças entre os defensores desta proposta e aqueles que sustentavam a educação em escolas inclusivas defendida pelo governo federal. Os defensores da escola bilíngue foram acusados de serem segregacionistas, desconsiderando toda caminhada que já estava contemplada nos documentos que lhes asseguravam a especificidade da escola bilíngue para surdos (NASCIMENTO, 2017, p. 79).

Com o documento final do CONAE2010, desconsiderando os apelos da comunidade surda, foi necessária uma atuação firme do Movimento Surdo, representado pela Feneis para que fosse alterada, no documento final do PNE 20142024 (BRASIL, 2014), a redação para incluir, além do espaço escolar inclusivo, em escolas regulares, escolas e classes bilíngues para a instrução de surdos, no Brasil.

É nesse contexto que a educação bilíngue, dentro do espaço da escola comum, se mostra frágil e incapaz de oferecer língua de sinais em sua plenitude aos surdos, em especial por termos, estatisticamente, a grande maioria de surdos filhos de pais ouvintes (CROMACK, 2004). Assim, a 


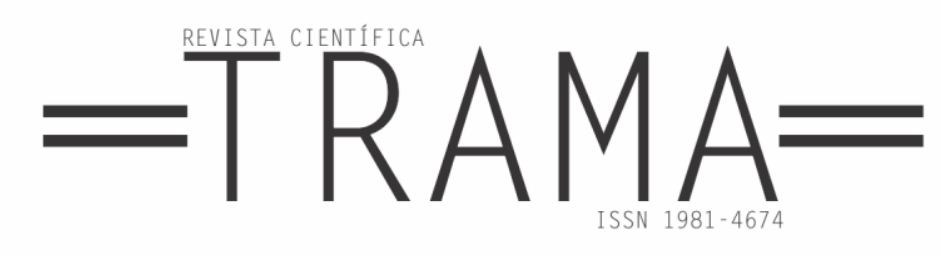

língua de sinais precisa ser ofertada de modo natural na escola. Para o Movimento Surdo, do modo como têm se apresentado as condições de inclusão, isso não é viável (CAMPELLO; REZENDE, 2014).

Dessa forma, a demanda da agenda do Movimento Surdo não para de crescer, é necessário que a lei se materialize em ações políticas que venham ao encontro dos anseios das comunidades surdas brasileiras, a exemplo do que aconteceu com o PNE, devendo ser contempladas para ressoarem no espaço das instituições escolares.

\section{Considerações finais}

O presente estudo destacou o Movimento Surdo e sua atuação frente à oficialização da Libras no Brasil e a incansável busca por políticas linguísticas. Sua importante representatividade como órgão não governamental, em especial a Feneis, foi e é imperativo para a criação de políticas linguísticas que entendam o surdo na perspectiva de diferença cultural e linguística, superando o modelo clínicoterapêutico que apenas o vê e entende pela ausência da audição e/ou comprometimento da mesma e visa sua reabilitação, normalização que legitima a violência simbólica fruto do ouvintismo.

Nesse contexto, as pesquisas acadêmicas também desempenham papel relevante. A academia, campo privilegiado de estudo, em consonância com o Movimento Surdo, tem possibilitado avanços na legitimação da Libras como língua e seus desdobramentos para o desenvolvimento integral do surdo.

Verifica-se que muitas conquistas têm sido alcançadas ao surdo, legalmente, nas últimas décadas, mas há, sem dúvida, a necessidade de contínua vigilância e prontidão para a luta. Afinal, garantia legal não necessariamente significa mudanças de práticas. E é nesse contexto que a luta continua. Luta-se pelas leis e pelas ações para que, a partir delas, criem-se reais mudanças às práticas.

\section{$\mathbf{R}_{\text {EFERÊnCIAS }}$}

ASSIS SILVA, C. A. Cultura surda: agentes religiosos e a construção de uma identidade. São Paulo: Terceiro Nome, 2012.

BARBERENA, C. F. R. Cultura surda: imperativo pedagógico nos discursos que circulam na Anped no período de 1990 a 2010. In: REUNIÃO ANUAL DA ANPED, 26., 2013, Goiânia. Disponível em: http://36reuniao.anped.org.br/pdfs_trabalho s_aprovados/gt15_trabalhos_pdfs/ gt15_3377_texto.pdf. Acesso em: jul. 2017.

BOURDIEU, P. A Dominação Masculina: A condição feminina e a violência simbólica. Rio de Janeiro: BestBolso, 2014.

\section{BRASIL. Declaração de Salamanca e linha de ação sobre necessidades educativas especiais. Brasília: UNESCO, 1994.}

BRASIL. Lei $\mathbf{N}^{\mathbf{o}}$. 10.436, de 24 de abril de 2002. Brasília: Presidência da República, Casa Civil, Subchefia para Assuntos Jurídicos, 2002. Disponível em: http://www.planalto.gov.br/ccivil_03/leis/2 002/110436.htm. Acesso em:10 out. 2017.

BRASIL. Decreto $\mathbf{n}^{\mathbf{0}} \mathbf{5 . 6 2 6}$, de 22 de dezembro de 2005. Brasília: Presidência da República, Casa Civil, Subchefia para Assuntos Jurídicos. Disponível em: http://www.planalto.gov.br/ccivil_03/_ato2 004-2006/2005/decreto/d5626.htm. Acesso em:10 out. 2017.

BRASIL. Lei $\mathrm{n}^{\circ} 13005$ de 25 de junho de 2014. Aprova o Plano Nacional de Educação - PNE e dá outras providências. Diário Oficial da República Federativa do Brasil, Poder Executivo, Brasília, DF, 26 de jun. de 2014. Disponível em: http://fne.mec.gov.br/images/doc/LeiPNE.p df. Acesso em: 10 out. 2016.

BRITO, F. B. O movimento social surdo e a campanha pela oficialização da língua brasileira de sinais. 168p. 2013. Tese 


\section{$=\mathrm{T}$ RAMA $=$}

(Doutorado) - Universidade de São Paulo USP, São Paulo, 2013.

BRITO, F. B.; NEVES, S. L. G.; XAVIER, A. N. O Movimento Surdo e sua luta pelo reconhecimento de libras e pela construção de uma política linguística no Brasil. In: ALBRES, N. de A.; NEVES, S.L. (Org.). Libras em estudo: política linguística. São Paulo: FENEIS, 2013.

CAMPELlO, A. L.; REZENDE. P. L. F. Em defesa da escola bilíngue para surdos: a história de lutas do Movimento Surdo brasileiro. Educar em Revista, Curitiba: Editora UFPR. Edição Especial, n.2, p. 7192, 2014.

CROMACK, E. M. P. da C. Identidade, cultura surda e produção de subjetividades e educação: atravessamentos e implicações sociais. Psicol. cienc. prof., v. 24, n.4, p. 6877. 2004. Disponível em: http://pepsic.bvsalud.org/scielo.php?script= sci_arttext\&pid=S1414-

98932004000400009. Acesso em: 23 out. 2017.

FELIPE, T. A relação sintático-semântica dos verbos e seus argumentos na LIBRAS. Tese (Doutorado) - Universidade Federal do Rio de Janeiro, Rio de Janeiro, 1998.

FERREIRA BRITO, L. Similarities and Differences in Two Sign Languages. Sign Language Studies, Silver Spring, v. 13, n. 42. USA, 1984.

FERREIRA BRITO, L. Uma abordagem Fonológica dos Sinais da LSCB. Espaço: informativo técnico científico do INES. Rio de Janeiro, INES, n.1, jul./dez. 1990.

FERREIRA BRITO, L. Integração Social e Educação de Surdos. Rio de Janeiro: Babel, 1993.

FERREIRA BRITO, L. Por uma gramática de Língua de Sinais. Rio de Janeiro: Tempo Brasileiro, 1995.

FERREIRA BRITO, L. Língua Brasileira de Sinais - LIBRAS. In: BRASIL. Ministério da Educação e do Desporto/Secretaria de Educação Especial. Série Atualidades pedagógicas, n.4, v III, 1998.

FERREIRA BRITO, L. Legislação e a língua de sinais. São Paulo: Ferreira e Bergoncci Consultoria e Publicações, 2003.

FERNANDES, S.; MOREIRA, L. C. Políticas de educação bilíngue para surdos: o contexto brasileiro. Educ. rev. [online]. 2014. Disponível em: http://www.scielo.br/scielo.php?pid=S0104

0602014000600005\&script=sci_abstract $\&$ tl ng=pt. Acesso em: 15 jul. 2017.

FERNANDES, E.; RIOS, K. R. Educação com bilingüismo para crianças surdas. Trabalho apresentado no Simpósio Educação com bilingüismo para crianças surdas. Intercâmbio, v. 3. 1998.

GLAT, R. A integração social dos portadores de deficiência: uma reflexão. 3.ed. Rio de Janeiro: 7 Letras, 2006.

GLAT, R.; MASCARO, C. A. A. de C.; ANTUNES, K. C. V.; MARIN, M. Inclusão de pessoas com deficiência e outras necessidades especiais na escola e no trabalho. Cadernos CIEE, 1. ed., 2011.

HALL, S. Identidade Cultural e Diáspora. Revista do Patrimônio Histórico e Artístico Nacional, n.24, p. 68-75. 1996.

KARNOPP, L. B. Aquisição do parâmetro configuração de mão na Língua Brasileira de Sinais (LIBRAS): estudo sobre quatro crianças surdas, filhas de pais surdos. Dissertação (Mestrado) - Pontifícia Universidade Católica do Rio Grande do Sul - PUCRS, 1994.

KARNOPP, L. B. Aquisição Fonológica na Língua Brasileira de Sinais: estudo longitudinal de uma criança surda. Tese (Doutorado) - Pontifícia Universidade Católica do Rio Grande do Sul, PUCRS, 1999. 


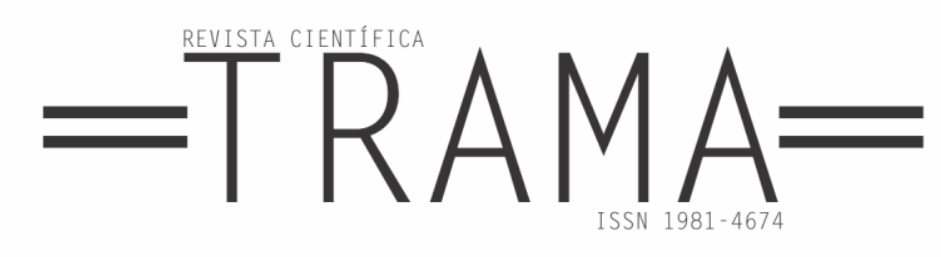

KLEIN, M. Diversidade e igualdade de oportunidades: estratégia de normalização nos movimentos sociais surdos. In: THOMA, A. S.; LOPES, M. C. (Orgs). A invenção da surdez II: espaços e tempos de aprendizagem na educação de surdos. Santa Cruz do Sul: EDUNISC, 2006.

LANE, H. A máscara da benevolência: a comunidade surda amordaçada. Lisboa: Instituto Piaget, 1992.

MAZZOTTA. M. J. S.; D'ANTINO, M. E. F. Inclusão social de pessoas com deficiências e necessidades especiais: cultura, educação e lazer. Saude Soc., São Paulo, v. 20, n. 2, abr./jun. 2011.

MONTEIRO, M. S. História dos movimentos dos surdos e o reconhecimento da Libras no Brasil. Educação Temática Digital, v. 7, n. 2, p. 279-289, 2006. Disponível em: http://143.106.58.55/revista/index. php. Acesso em: 22 jan. 2017.

MORAES, V. P.; SANTOS, A. N. Nada de nós, sem nós: a produção da cultura surda na contemporaneidade. In: ENDIPE - Encontro Nacional de Didática e Prática de Ensino, 17., 2015, Fortaleza - CE. Título: Didática e a prática de ensino na relação com a sociedade. Fortaleza - CE: EdUECE, 2015.

NASCIMENTO. A. C. e S. G. O direito à Libras como língua materna: um estudo sobre a política Educacional de Educação Infantil para crianças surdas na rede municipal de ensino de Curitiba. Dissertação (Mestrado em Educação) - Universidade Federal do Paraná - UFPR, Curitiba, 2017.

OMOTE, S. Estigma no tempo da inclusão. Revista Brasileira de Educação Especial, v.10, n.3, p. 257-272, set-dez. 2004.

PEIXOTO, R. C. Algumas considerações sobre a interface entre a Língua Brasileira de Sinais (LIBRAS) e a Língua Portuguesa na construção inicial da escrita pela criança surda. Cad. CEDES, v. 26, n.69, p. 205-229. 2006.
QUADROS, R. M. de. Educação de surdos: a aquisição da linguagem. Porto Alegre: Artes Médicas, 1997.

QUADROS, R. M.; CAMPELLO, A. R. e S. A constituição política, social e cultural da língua brasileira de sinais-Libras. In: VIEIRA-MACHADO, L. M. C; LOPES, M. C. (Org.). Educação de Surdos: políticas, língua de sinais, comunidade e cultura surda. Santa Cruz do Sul: EDUNISC, 2010.

RAMOS, C. R. Libras: a língua de sinais dos surdos brasileiros. 2007. Disponível em: http://www.editora-arara-

azul.com.br/pdf/artigo2.pdf. Acesso em: 24 jan. 2017.

SACKS, O. Vendo vozes: uma viagem ao mundo dos surdos. São Paulo: Companhia das Letras, 1998.

SILVA, V. Educação de Surdos: uma releitura da primeira escola pública para surdos em Paris e do Congresso de Milão em 1880. In: QUADROS, R. M. Estudos Surdos I. Petrópolis: Arara Azul, 2006.

SOUZA, R. M. de. Que palavra te falta? Linguística, educação e surdez. São Paulo: Martins Fontes, 1998.

STOKOE, W. Sign Language Structure: An outline of the visual communication systems of the american deaf. Studies in Linguistics, n. 8, University of Buffalo, 1960.

THOMA, A. S.; KLEIN, M. Experiências educacionais, movimentos e lutas surdas como condições de possibilidade para uma educação de surdos no Brasil. Cadernos de Educação, Pelotas, RS, n. 36, p. 107-131, maio/ago. 2010. 